BMJ Open

Diabetes

Research

\& Care

\title{
Socioeconomic status and glycemic control in adult patients with type 2 diabetes: a mediation analysis
}

Janie Houle, ${ }^{1,2}$ François Lauzier-Jobin, ${ }^{1}$ Marie-Dominique Beaulieu, ${ }^{2,3}$ Sophie Meunier, ${ }^{1}$ Simon Coulombe, ${ }^{1}$ José Côté, ${ }^{2,4}$ François Lespérance, ${ }^{2,5}$ Jean-Louis Chiasson, ${ }^{2,6}$ Louis Bherer, ${ }^{7,8}$ Jean Lambert ${ }^{9}$

To cite: Houle J, LauzierJobin F, Beaulieu M-D, et al. Socioeconomic status and glycemic control in adult patients with type 2 diabetes: a mediation analysis. BMJ Open Diabetes Research and Care 2016;4:e000184. doi:10.1136/bmjdrc-2015000184

Received 14 December 2015 Revised 27 February 2016 Accepted 22 March 2016
CrossMark

For numbered affiliations see end of article.

Correspondence to

Dr Janie Houle;

houle.janie@uqam.ca

\section{ABSTRACT}

Objective: The purpose of this study is to examine the contribution of health behaviors (self-management and coping), quality of care, and individual characteristics (depressive symptoms, self-efficacy, illness representations) as mediators in the relationship between socioeconomic status (SES) and glycemic control.

Methods: A sample of 295 adult patients with type 2 diabetes was recruited at the end of a diabetes education course. Glycemic control was evaluated through glycosylated hemoglobin $\left(\mathrm{HbA}_{1 \mathrm{c}}\right)$. Living in poverty and education level were used as indicators of SES.

Results: Bootstrapping analysis showed that the significant effects of poverty and education level on $\mathrm{HbA}_{1 \mathrm{c}}$ were mediated by avoidance coping and depressive symptoms. The representation that diabetes is unpredictable significantly mediated the relationship between living in poverty and $\mathrm{HbA}_{1 \mathrm{c}}$, while healthy diet mediated the relationship between education level and $\mathrm{HbA}_{1 \mathrm{c}}$.

Conclusions: To improve glycemic control among patients with low SES, professionals should regularly screen for depression, offering treatment when needed, and pay attention to patients' illness representations and coping strategies for handling stress related to their chronic disease. They should also support patients in improving their self-management skills for a healthy diet.

\section{INTRODUCTION}

Socioeconomic status (SES) refers to the social and economic position that a person occupies within a given social structure. Most of the leading causes of death and disability are related to SES, including diabetes. ${ }^{1}{ }^{2}$ Individuals with low SES are more likely to suffer from type 2 diabetes. ${ }^{3-6}$ When glycemic control is not optimal, that is, when glycosylated hemoglobin $\left(\mathrm{HbA}_{1 \mathrm{c}}\right)$ is over $7.0 \%,{ }^{7}$ diabetes can have severe consequences, such as retinopathy, nephropathy, and cardiovascular disease. Individuals with low SES also have worse glycemic control than those with higher SES, ${ }^{8-10}$ which leads

\section{Key messages}

- Education level and living in poverty are associated with glycemic control among patients with type 2 diabetes.

- Education level and living in poverty are indirectly associated with worse glycemic control through avoidance coping and depressive symptoms.

- The representation that diabetes is unpredictable significantly mediated the relationship between living in poverty and glycemic control, while healthy diet mediated the relationship between education level and glycemic control.

to more complications of their disease, including a higher mortality rate. ${ }^{1-13}$

\section{Theoretical framework}

Although the negative association between SES and glycemic control has often been demonstrated, it remains largely unexplained. On the basis of a review of more than 250 articles, Brown et al ${ }^{14}$ proposed a conceptual framework that identifies three sets of mediating variables representing the mechanisms linking SES to diabetes health outcomes (such as glycemic control): health behaviors, quality of care and individual characteristics.

\section{Health behaviors}

Type 2 diabetes requires rigorous patient selfmanagement, involving daily dietary decisions, physical activity, blood glucose monitoring and consistent medication adherence. While these behaviors are crucial to ensure optimal glycemic control,,${ }^{9}{ }^{15}$ low SES is associated with poorer diabetes selfmanagement. ${ }^{15-17}$ The first empirical study that tried to validate a modified version of Brown's ${ }^{18}$ conceptual framework, conducted among a sample of 615 adults with type 2 diabetes recruited from primary care clinics in the USA, found that the influence of SES 
on glycemic control was not mediated by selfmanagement behaviors. However, this study used only medication adherence to assess self-management behaviors and did not measure other important behaviors such as exercise, blood glucose testing, or healthy diet.

Given its potential complications, its sometimes disruptive symptoms (such as hypoglycemia), and the demanding nature of the self-management behaviors it requires, diabetes is an illness that can generate significant stress. ${ }^{19}$ In individuals with low SES, this is added to the stress that comes from being exposed to high financial strain, poor job conditions, inadequate housing, and devitalized neighborhoods. ${ }^{20}$ Coping strategies are needed to handle this stress and minimize its deleterious effect on the course of the illness. Persons with diabetes use various strategies to cope with stress, and these have been associated with glycemic control in several studies. $^{21-23}$ For example, investing more in emotionfocused coping (eg, getting emotional support from others) than in problem-focused coping (eg, taking action to make the situation better) is associated with poor glycemic control. ${ }^{23}$ Studies have shown that persons with low SES report using less active coping strategies $^{24} 25$ than do persons with higher SES. Coping strategies may therefore help explain the relationship between SES and glycemic control.

\section{Quality of care}

Brown's conceptual framework ${ }^{14}$ identifies access to care and process of care as potential mediators in the relationship between SES and glycemic control. While good quality of diabetes care was associated with better glycemic control in previous studies, ${ }^{26}{ }^{27}$ patients with low SES received poorer care: they were diagnosed later, had lower access to diabetes self-management education programs, underwent hemoglobin monitoring less often, and had fewer foot and eye dilation examinations. ${ }^{28-30} \mathrm{~A}$ study by Walker et $a l^{18}$ supports this aspect of Brown's model by showing that the association between income and glycemic control is mediated by patient-centered care and participation in diabetes education classes.

\section{Individual characteristics}

Brown's conceptual framework ${ }^{14}$ also identified individual characteristics as potential mediators between SES and health outcomes of patients with diabetes. ${\text { Depressive } \text { symptoms }^{31} \text { and self-efficacy }}^{32}$ have been found to be mediating variables between SES and $\mathrm{HbA}_{1 \mathrm{c}}$ in previous studies. This suggests that persons with low SES are more depressed and have less confidence in their ability to adopt diabetes self-management behaviors, and, as a result, their glycemic control is not as good as that of persons with higher SES.

Illness representations could be an additional individual mediator. Illness representations are systems of personal beliefs one adheres to concerning diabetes. ${ }^{33}$ "Patients create their own 'models' or representations of their illness that then influence their coping and care- seeking behavior" (ref. 34, p. 176). Representations of illness vary along dimensions such as timeline (belief about predictability, chronic vs acute nature), consequences (awareness of the severity of the disease), and treatment control (expected efficacy of the treatment in controlling the disease). ${ }^{34}{ }^{35}$ Studies have shown that illness representations are associated with diabetes selfmanagement behaviors and glycemic control. ${ }^{36-39}$ To our knowledge, there is no study that has examined the association between SES and illness representations in diabetes. It is possible that, due to more difficult life circumstances and poorer health literacy, persons with diabetes with low SES have a representation of illness that differs from that of persons with higher SES. This might help explain the effect of SES on glycemic control. However, this has not been investigated.

Within Brown's conceptual framework, ${ }^{14}$ it is important to distinguish between individual characteristics (such as those presented above), which are considered as mediators between SES and health outcomes, and covariates (such as age, sex, and ethnicity), which are critical but should be considered in terms of their independent effect on health outcomes.

\section{Study purpose}

The purpose of this cross-sectional study is to explore further the association between SES and glycemic control, by examining, according to Brown's conceptual framework, ${ }^{14}$ the contribution of three sets of mediators: health behaviors (diabetes self-management behaviors, and coping strategies with diabetes-related stress), quality of care (Patient Assessment of Chronic Illness Care (PACIC)), and individual characteristics (depression, diabetes self-efficacy, and illness representations).

\section{METHODS}

\section{Recruitment and procedures}

The project received approval from the appropriate ethical review boards. Participants were recruited at the end of a diabetes education course given at four hospitals and four health and social services centers (HSSCs) in Montreal and Laval, two cities in the province of Québec, Canada. Inclusion criteria were: (1) having been diagnosed with type 2 diabetes at least 3 months prior; (2) being 18 years of age or older; (3) being able to read and speak English or French fluently. Pregnant women were excluded. Participants signed a consent form. They received \$C20 as compensation for completing the measurement questionnaire.

\section{Measurements}

Income, level of education, or occupational status are usually used to measure SES, ${ }^{1}{ }^{40}$ but these indicators cannot be used interchangeably as they may have different pathways and effects on a selected outcome. ${ }^{1} 40{ }^{41}$ Thus, in the present study, each SES indicator was examined separately. Income level was conceptualized as 
living in poverty (below the poverty threshold established by the National Population Health Survey). Level of education was measured according to the highest level of schooling completed: elementary school (sixth grade or less), incomplete high school, high school, college, or university. To compare it more easily with living in poverty, which has two levels (yes; no), education level was dichotomized $(0=$ high school diploma or less; $1=$ college degree or more). Type of occupation was not considered in our study because a large proportion of patients were retired. The correlation between the two SES indicators used in this study (living in poverty and education level) was moderate $(\mathrm{r}=-0.20, \mathrm{p}<0.01)$, indicating that the two variables are related yet distinct.

$\mathrm{HbA}_{1 \mathrm{c}}$, an indicator of glycemic control over a 2-3-month period, was the dependent variable in our analyses. It was measured with an A1CNow+ device (Bayer Health Care, Sunnyvale, California, USA, 2011). This device has been shown to provide measurements that are overall consistent with a standard laboratory testing method. ${ }^{42}$

Five diabetes self-management behaviors were evaluated with a valid self-report instrument, the Summary of Diabetes Self-Care Activities-Revised ${ }^{43}$ healthy diet $(\alpha=0.87)$, exercise $(\alpha=0.78)$, blood glucose testing $(\alpha=0.87)$, medication adherence $(\alpha=0.71)$, and smoking. Participants were asked to indicate the number of days they performed their self-management activities over the last 7 days.

Coping strategies were examined with the Brief-COPE instrument. ${ }^{44}$ This questionnaire consists of 28 items grouped into 14 subscales. For each item, participants indicated on a four-point Likert scale (1=not at all; $4=\mathrm{a}$ lot) how much they used a given strategy when faced with diabetes-related stress. To reduce the number of variables to be included in the analysis, the original subscales were grouped into four larger subscales: ${ }^{45}$ emotional coping (venting and emotional support; $\alpha=0.80$ ), behavioral coping (active coping, planning, and instrumental support; $\alpha=0.77$ ), cognitive coping (acceptance, positive reframing, humor, and religion; $\alpha=0.72$ ), and avoidance coping (substance use, denial, behavioral disengagement, and self-distraction; $\alpha=0.63$ ).

Quality of care was measured with the PACIC ${ }^{46}$ $(\alpha=0.94)$. This 20 -item self-report questionnaire asked the patients to rate on a five-point scale (1=none of the time; $5=$ always) the frequency with which they receive care that is patient-centered, proactive, planned, and that includes collaborative goal setting, problem-solving and follow-up support. The PACIC is a reliable $(\alpha=0.96)$ and valid instrument. ${ }^{46} 47$

Depressive symptoms were evaluated using the Patient Health Questionnaire-9 (PHQ-9), ${ }^{48}$ a brief self-assessment tool that asks participants to rate the frequency of nine depressive symptoms over the previous 2 weeks. This measure is reliable $(\alpha=0.83)$ and valid, with high sensitivity and specificity in primary care and community studies of diabetes. ${ }^{48} 49$
Diabetes self-efficacy was measured using the Diabetes Management Self-Efficacy Scale..$^{50}$ This 20-item instrument has a good internal consistency $(\alpha=0.88)$, temporal stability $(\mathrm{r}=0.76)$, and convergent validity $(\mathrm{r}=0.52$ for General Self-Efficacy). ${ }^{50} 51$

Illness representations were evaluated using the seven subscales of the Revised Illness PerceptionQuestionnaire (IPQ-R): ${ }^{35}$ (1) consequences (beliefs about effects and impact of diabetes; $\alpha=0.70$ ); (2) personal control (own control over management; $\alpha=0.75)$; (3) treatment control (outcome expectancies of treatment and recommended advice; $\alpha=0.59$ ); (4) timeline acute/chronic (perceived length of illness; $\alpha=0.87$ ); (5) timeline cyclical (unpredictable cyclical nature of illness; $\alpha=0.82$ ); (6) emotional representations (affective response to illness; $\alpha=0.90$ ); and (7) coherence (overall understanding of illness; $\alpha=0.83$ ).

In line with Brown et al, ${ }^{14}$ who mentioned the importance of including critical covariates, the following demographic and clinical covariates were included: age (in years), sex, immigration status (being born outside Canada or not), years since diagnosis, and insulin use (yes or no).

\section{Statistical analysis}

The aim of the present study was to test the indirect effects of SES on glycemic control $\left(\mathrm{HbA}_{1 \mathrm{c}}\right)$ through different mediators while controlling for potential confounding covariates. Bootstrapping is a resampling procedure that involves creating several different samples from the existing data set. Indirect effects are estimated in each resampled dataset, and CIs are derived from the bootstrap sample distribution. ${ }^{52}$ It is the currently recommended approach for testing mediation because it has more power, maintains reasonable control over the type I error rate, and represents the most powerful and reasonable method for obtaining confidence limits for all indirect effects. ${ }^{52-54}$ Using the INDIRECT macro developed by Preacher and Hayes (http://www.comm.ohio-state. edu/ahayes/SPSS\%20programs/indirect.htm), two confidence levels $(0.95$ and 0.99$)$ were used for the CIs of the mediators and 5000 bootstrap resamples. Analyses were performed using SPPS V.21 (SPSS Inc., USA).

\section{RESULTS}

\section{Participants}

Of the 1097 individuals invited to participate in the study, $295(26.9 \%)$ completed the questionnaires. Participants who did not provide information on their household income $(\mathrm{n}=11 ; 3.7 \%)$ were excluded. The final sample included 284 participants, whose sociodemographic and clinical information is presented in table 1.

\section{Mediation analysis}

After adjusting for covariates (age, sex, immigrant status, number of years since diagnosis, insulin use), the bootstrap results indicated that both SES indicators-living in 


\section{Table 1 Sample characteristics}

\begin{tabular}{|c|c|}
\hline Total, $\mathrm{n}$ & 284 \\
\hline Male, n (\%) & $144(50.7)$ \\
\hline Female, n (\%) & $140(49.3)$ \\
\hline \multicolumn{2}{|l|}{ Age, years } \\
\hline Mean (SD) & $59.3(10.8)$ \\
\hline Minimum-maximum, years & $31-83$ \\
\hline \multicolumn{2}{|l|}{ Immigration status, $\mathrm{n}(\%)$} \\
\hline Born in Canada & $219(77.1)$ \\
\hline Born outside Canada & $65(22.9)$ \\
\hline \multicolumn{2}{|l|}{ Education level, n (\%) } \\
\hline High school or less & $144(50.7)$ \\
\hline College or more & $140(49.3)$ \\
\hline \multicolumn{2}{|l|}{ Living in poverty, n (\%) } \\
\hline Yes & $83(29.2)$ \\
\hline No & $201(70.8)$ \\
\hline \multicolumn{2}{|l|}{ Diabetes duration, years } \\
\hline Mean (SD) & $7.4(7.8)$ \\
\hline Minimum-maximum, years & $0.25-52$ \\
\hline \multicolumn{2}{|l|}{ Insulin use } \\
\hline Yes & $62(21.8)$ \\
\hline No & $222(78.2)$ \\
\hline $\mathrm{HbA}_{1 \mathrm{c}}, \%(\mathrm{mmol} / \mathrm{mol})$ mean (SD) & $7.2(1.4)$ \\
\hline \multicolumn{2}{|c|}{$\mathrm{HbA}_{1 \mathrm{c}}$ level by poverty status and education level } \\
\hline Living in poverty: yes & $7.6(1.6)$ \\
\hline Living in poverty: no & $7.0(1.3)$ \\
\hline Education level: high school or less & $7.3(1.6)$ \\
\hline Education level: college degree or more & $7.0(1.1)$ \\
\hline
\end{tabular}

poverty and education level-were significantly related to glycemic control-as measured by $\mathrm{HbA}_{1 \mathrm{c}}$. The association between living in poverty and $\mathrm{HbA}_{1 \mathrm{c}}$ was mediated by three variables: cyclical representation of illness, avoidance coping, and depressive symptoms (see table 2). Self-management behaviors and quality of chronic illness care were not significant mediators. Thus, the association between living in poverty and $\mathrm{HbA}_{1 \mathrm{c}}$ was explained by the fact that living in poverty is associated with a greater tendency to believe that diabetes is an unpredictable and cyclical illness; by more frequent use of avoidance coping strategies, such as denial or disengagement; and by a greater number of depressive symptoms. It was a full mediation, as the association between living in poverty and $\mathrm{HbA}_{1 \mathrm{c}}$ was no longer significant when each mediator was taken into account. ${ }^{55}$

Avoidance coping, depressive symptoms, and healthy diet explained the association between education level and $\mathrm{HbA}_{1 \mathrm{c}}$ (see table 2), after adjusting for covariates. Higher educational attainment was associated with less frequent use of avoidance coping, with fewer depressive symptoms, and with a healthier diet. There was a full mediation for avoidance coping. However, for depressive symptoms and healthy diet, the association between education level and $\mathrm{HbA}_{1 \mathrm{c}}$ persisted even when mediators were taken into account, which indicates a partial mediation. ${ }^{55}$

\section{DISCUSSION}

Results from the present study showed that living in poverty and education level were related to glycemic control among patients with type 2 diabetes. Even in a universal-access healthcare system such as the Canadian one, social inequalities in health were still present. Our findings suggest that the effect of SES on glycemic control is mediated by the way patients perceive their disease, by how they cope with stress related to the illness, by their diet, and finally, by their depressive symptoms. Since diabetes is much more prevalent in populations with low SES and since failure to maintain optimal glycemic control enhances the risk of severe complications and death, these results have important practical implications.

This study found that participants with low SES were more likely to use avoidance coping during a stressful event related to their diabetes (eg, by giving up trying to

Table 2 Simple mediator effects in the relationships between living in poverty, education level, and $\mathrm{HbA}_{1 \mathrm{c}}$

\begin{tabular}{|c|c|c|c|c|c|c|}
\hline & $\begin{array}{l}\text { Total } \\
\text { effect }\end{array}$ & $\begin{array}{l}\text { Effect } \\
\text { IV-MV }\end{array}$ & $\begin{array}{l}\text { Effect } \\
\text { MV-DV }\end{array}$ & $\begin{array}{l}\text { Direct } \\
\text { effect }\end{array}$ & $\begin{array}{l}\text { Indirect } \\
\text { effect }\end{array}$ & $\begin{array}{l}\mathrm{BC} 95 \% \mathrm{Cl} \text { of } \\
\text { indirect effect }\end{array}$ \\
\hline \multicolumn{7}{|l|}{ Independent variable (IV) } \\
\hline Living in poverty & $0.37^{*}$ & & & & & \\
\hline \multicolumn{7}{|l|}{ Mediators (MV) } \\
\hline Timeline cyclical & & $0.39^{\star *}$ & $0.18^{*}$ & 0.30 & $0.07^{*}$ & 0.0084 to 0.1815 \\
\hline Avoidance coping & & $0.14^{\star}$ & $0.52^{\star \star}$ & 0.28 & $0.07^{\star}$ & 0.0091 to 0.2418 \\
\hline Depressive symptoms & & $2.12^{* *}$ & $0.04^{*}$ & 0.29 & $0.08^{*}$ & 0.0116 to 0.2202 \\
\hline \multicolumn{7}{|l|}{ Independent variable (IV) } \\
\hline Education level & $-0.35^{\star \star}$ & & & & & \\
\hline \multicolumn{7}{|l|}{ Mediators (MV) } \\
\hline Healthy diet & & $0.50^{*}$ & $-0.09^{\star}$ & $-0.29^{\star}$ & $-0.05^{\star}$ & -0.1422 to -0.0045 \\
\hline Avoidance coping & & $-0.21^{\star *}$ & $0.50^{\star *}$ & -0.24 & $-0.10^{\star}$ & -0.2637 to -0.0153 \\
\hline Depressive symptoms & & 1.11 & $0.04^{\star \star}$ & $-0.31^{*}$ & $-0.04^{*}$ & -0.1487 to -0.0002 \\
\hline
\end{tabular}

Only significant results are reported. Effects are adjusted for sex, age, immigration status, years with diabetes, and insulin use.

${ }^{*} \mathrm{p}<0.05 ;{ }^{* *} \mathrm{p}<0.01$.

$\mathrm{BC}$, bias corrected; DV, dependent variable; $\mathrm{HbA}_{1 \mathrm{c}}$, glycosylated hemoglobin. 
deal with the event or refusing to believe that it is happening) and that this coping style explained the relationship between the two SES indicators (living in poverty and education level) and $\mathrm{HbA}_{1 \mathrm{c}}$. Avoidance coping has previously been found to be negatively associated with glycemic control in a study among adolescents with type 1 diabetes, ${ }^{56}$ but this is the first time that its role as a mediator in the association between low SES and glycemic control in patients with type 2 diabetes is investigated. A cross-lagged longitudinal approach has suggested that avoidance coping increases as glycemic control worsens. ${ }^{57}$ Thus, the weaker glycemic control observed in participants with low SES could explain why they engaged in more avoidance coping than did participants with higher SES. However, given the inequitable distribution of power and resources in society as a whole, ${ }^{58}$ persons with low SES are more likely to face cumulative adverse life circumstances that generate a lot of chronic stress. ${ }^{59}$ In this difficult context, diabetes could be seen as an additional stressor that receives lower priority than other potentially more urgent problems already occupying the attention of persons with low SES, such as being able to eat three meals per day or finding decent housing. It is important not to 'blame the victim' by focusing only on individual determinants of health. That being said, interventions aimed at helping patients to actively cope with the stress of managing a chronic disease such as diabetes could be useful. ${ }^{60}$ Professionals should consider asking their patients who have diabetes how they react when facing a stressful event related to their diabetes and, when appropriate, should try to help them plan active coping strategies to replace avoidant ones.

Depressive symptoms were also found to be a significant mediator in the relationship between SES indicators and glycemic control. This result is convergent with a previous study among rural African-Americans. ${ }^{31}$ Depressive symptoms were more prevalent in populations with low SES, ${ }^{61}$ probably because of financial strain, job insecurity, stigmatization, etc. Populations with low SES are subject to high levels of chronic stress that increase their risk of developing depression and diabetes. ${ }^{20}$ Numerous studies have found an association between depressive symptoms and glycemic control. ${ }^{62}$ When patients are struggling with depression, they are no longer able or willing to adopt self-management behaviors required for their diabetes. It is important to screen persons with diabetes regularly for depressive symptoms, using a very brief tool such as the PHQ-9, ${ }^{48}$ and to offer those suffering from depression appropriate pharmacological or psychotherapeutic treatment. ${ }^{63}$ However, low SES could be a significant barrier to accessing treatment for depression, ${ }^{64}$ particularly if the person has no health insurance ${ }^{65}$ and many studies have shown that improvements in depressive symptoms do not necessarily result in improved $\mathrm{HbA}_{1 \mathrm{c}}{ }^{66}{ }^{67}$ More research is needed to better understand the relationship between low SES, depressive symptoms and glycemic control.
Consistent with Walker et $a l^{18}$ this study found that medication adherence did not mediate the association between SES and $\mathrm{HbA}_{1 \mathrm{c}}$. However, in the present study, healthy diet was a significant mediator in the relationship between education level and glycemic control. Patients with a higher education level (college or university degree) were more likely to follow a healthy diet and thus their $\mathrm{HbA}_{1 \mathrm{c}}$ level was lower. A previous study identified health literacy as a mediator between education level and glycemic control. ${ }^{68}$ It is possible that in the present study, participants with a higher level of education found it easier to read and understand nutritional information required to follow a healthy diet, but this hypothesis needs to be tested.

Results also revealed that patients living in poverty scored higher on the timeline cyclical subscale of the IPQ-R and that this illness representation fully mediated the association between SES and glycemic control. Believing that diabetes is unpredictable and cyclical suggests a lack of perceived control over the illness. It is possible that people living in poverty may interpret unsuccessful efforts to improve their glycemic control as an indication of the unpredictable nature of diabetes. The consistently higher $\mathrm{HbA}_{1 \mathrm{c}}$ and the greater incidence of severe hypoglycemia among persons with low $\mathrm{SES}^{69}$ might further contribute to this negative belief. A systematic review reported a positive association between timeline cyclical and $\mathrm{HbA}_{1 \mathrm{c}}(\mathrm{r}=0.26)^{39}$ and concluded that this illness representation has the greatest correlation with $\mathrm{HbA}_{1 \mathrm{c}}$. There is some evidence that illness representations can be positively changed through targeted intervention and that these changes may also impact glycemic control, ${ }^{70}$ but to specifically modify the representation that diabetes is unpredictable, it would be necessary to demonstrate more clearly to patients the influences of their self-management behaviors on their levels of $\mathrm{HbA}_{1 \mathrm{c}}$. Carefully monitoring self-management behaviors, using a short questionnaire such as the Summary of Diabetes Self-Care, ${ }^{43}$ and regularly measuring $\mathrm{HbA}_{1 \mathrm{c}}$ could help patients visualize their progress, regain confidence in the control they have over the course of the illness, and lessen their representation of diabetes as unpredictable. Patients could choose small, realistic, and motivational self-management objectives, supported by health professionals and family members. It is possible to enhance self-management behaviors and glycemic control of socioeconomically vulnerable populations, but interventions need to be tailored to their context, preferences and priorities. ${ }^{71}$

Finally, contrary to Walker's findings, ${ }^{18}$ results did not support the mediating role of quality of care in the relationship between SES and glycemic control. Participants in the present study were recruited in group education classes provided in hospitals and community health center settings and may have received a higher quality of care than patients recruited in primary care, which could have lessened the differences between low and high SES status experience of care. 
This study focused on behavioral and psychological barriers to optimal diabetes management among patients with low SES. However, this vulnerable population faces numerous other economic, social, and structural barriers. ${ }^{72}$ For example, lack of financial means could limit their ability to afford medication, healthy food, blood glucose monitoring supplies, or transportation to care facilities. ${ }^{73}$ People with low income tend to live in underprivileged neighborhoods where there is little access to fresh fruits and vegetables or to safe green spaces and streets for outdoor exercising. ${ }^{74} 75$ Lower health literacy and diabetes-specific numeracy (ie, computational) skills undermine their capacity to understand and perform the self-management behaviors needed to control their chronic illness. ${ }^{76}$ Better communication between low-income patients and providers could improve medication adherence, ${ }^{78}$ a crucial selfmanagement behavior that is more likely to be deficient among low-income populations. ${ }^{9}$ It is vital that more research be conducted on the role of poverty and low education levels in producing the health inequalities that are seen in the case of diabetes and chronic diseases in general. ${ }^{79-81}$ Although improving healthcare quality is a determinant factor, it is not the entire solution to the problem of reducing social inequalities. ${ }^{82} 83$ It is also necessary to investigate the structural conditions that produce these inequalities by perpetuating poverty and low education. ${ }^{84}$

Finally, this study further supports the notion that the different SES indicators cannot be used interchangeably, as they may have different effects on a selected outcome through specific pathways. ${ }^{1} 40{ }^{41}$ Income and educational attainment are not only individual characteristics, but they are proxies for an overarching latent construct. Future studies could examine the influence of a large array of indicators, such as occupational status, deprivation index of the neighborhood of residence or subjective perception of socioeconomic position. ${ }^{85}$

\section{Limitations}

Participants were recruited in diabetes group education classes offered during the day in hospitals or HSSCs in urban settings. As such, the sample is not representative of patients followed solely by their family physician in regular care. In addition, while this mediation analysis is based on assumptions regarding directionality, it is not possible statistically to determine causality from this cross-sectional data. It is possible, for example, that a chronic depressive disorder might have led patients to live in poverty. Other limitations are that several of the data collection tools for the mediating variables were self-reporting tools and that participants' health literacy was not assessed. It would have been useful to measure participants' stress level, since cortisol has a negative influence on $\mathrm{HbA}_{1 \mathrm{c}}{ }^{86}$ Finally, although the point-of-care A1CNow+ device has been shown to have good measurement properties, ${ }^{42} 87$ results should be replicated by testing $\mathrm{HbA}_{1 \mathrm{c}}$ level from blood samples using gold standard laboratory testing (high-performance liquid chromatography). ${ }^{88}$

\section{Conclusion}

Our study found that the association between SES and glycemic control was explained by avoidance coping, depressive symptoms, the representation that diabetes is unpredictable, and healthy diet. These findings have implications for physicians, nurses, nutritionists and other health professionals working with patients who have diabetes and live in poverty or have low educational attainment. Further research should examine the mechanisms by which low SES impacts the management of diabetes so that we can better address social inequalities in health.

\section{Author affiliations}

${ }^{1}$ Department of Psychology, Université du Québec à Montréal, Montréal, Québec, Canada

${ }^{2}$ CRCHUM, Montréal, Québec, Canada

${ }^{3}$ Department of Family and Emergency Medicine, Université de Montréal, Montréal, Québec, Canada

${ }^{4}$ Faculty of Nursing, Université de Montréal, Montréal, Québec, Canada ${ }^{5}$ Department of Psychiatry, Université de Montréal, Montréal, Québec, Canada ${ }^{6}$ Department of Medicine, Université de Montréal, Montréal, Québec, Canada ${ }^{7}$ PERFORM Centre, Concordia University, Montréal, Québec, Canada

${ }^{8}$ Institut Universitaire de Gériatrie de Montréal, Montréal, Québec, Canada ${ }^{9}$ Department of Social and Preventive Medicine, School of Public Health, Université de Montréal, Montréal, Québec, Canada

Acknowledgements The authors wish to thank the following sites for their collaboration in recruiting participants: Hôpital Notre-Dame, Hôpital Hôtel-Dieu, Hôpital Maisonneuve-Rosemont, Hôpital Sacré-Coeur, and the CSSSs of Laval, Coeur de l'île, Ahuntsic et Montréal-Nord, and Verdun.

Contributors $\mathrm{JH}$ mentored the entire project and wrote part of the manuscript. FL-J and SM analyzed the data and wrote part of the manuscript. $\mathrm{M}-\mathrm{DB}, \mathrm{SC}, \mathrm{JC}, \mathrm{FL}, \mathrm{J}-\mathrm{LC}$, and LB reviewed/edited the manuscript and contributed to discussion. $\mathrm{JL}$ analyzed the data and reviewed/edited the manuscript.

Funding This research was supported by a grant from the Canadian Institutes of Health Research (MOP209365). Bayer Health Care provided the A1CNow+ device used to measure $\mathrm{HbA}_{1 \mathrm{c}}$ levels but has no involvement with the study.

\section{Competing interests None declared.}

Ethics approval This research project was approved by the ethics review boards of the Université du Québec à Montréal and of each participating institution.

Provenance and peer review Not commissioned; externally peer reviewed.

Data sharing statement No additional data are available.

Open Access This is an Open Access article distributed in accordance with the Creative Commons Attribution Non Commercial (CC BY-NC 4.0) license, which permits others to distribute, remix, adapt, build upon this work noncommercially, and license their derivative works on different terms, provided the original work is properly cited and the use is non-commercial. See: http:// creativecommons.org/licenses/by-nc/4.0/

\section{REFERENCES}

1. Agardh E, Allebeck P, Hallqvist J, et al. Type 2 diabetes incidence and socio-economic position: a systematic review and meta-analysis. Int J Epidemiol 2011;40:804-18.

2. Everson SA, Maty SC, Lynch JW, et al. Epidemiologic evidence for the relation between socioeconomic status and depression, obesity and diabetes. J Psychosom Res 2002;53:891-5. 
3. Maty SC, Everson-Rose SA, Haan MN, et al. Education, income occupation, and the 34-year incidence (1965-99) of Type 2 diabetes in the Alameda County Study. Int J Epidemiol 2005;34:1274-83.

4. Link CL, McKinlay JB. Disparities in the prevalence of diabetes: is it race/ethnicity or socioeconomic status? Results from the Boston Area Community Health (BACH) survey. Ethn Dis 2009;19:288-92.

5. Ross NA, Gilmour H, Dasgupta K. 14-year diabetes incidence: the role of socio-economic status. Health Rep 2010;21:19-28.

6. Lee TC, Glynn RJ, Peña JM, et al. Socioeconomic status and incident type 2 diabetes mellitus: data from the Women's Health Study. PLOS ONE 2011;6:e27670.

7. American Diabetes Association. Glycemic targets. Standards of medical care in diabetes. Diabetes Care 2016;39(Suppl 1):S39-46.

8. Jotkowitz $A B$, Rabinowitz $G$, Raskin Segal $A$, et al. Do patients with diabetes and low socioeconomic status receive less care and have worse outcomes? A national study. Am J Med 2006;119:665-9.

9. Houle J, Beaulieu MD, Chiasson JL, et al. Glycaemic control and self-management behaviours in type 2 diabetes: results from a 1-year longitudinal cohort study. Diabet Med 2015;32:1247-54.

10. James GD, Baker P, Badrick E, et al. Ethnic and social disparity in glycaemic control in type 2 diabetes; cohort study in general practice 2004-9. J R Soc Med 2012;105:300-8.

11. Chaturvedi N, Jarrett J, Shipley MJ, et al. Socioeconomic gradient in morbidity and mortality in people with diabetes: cohort study findings from the Whitehall study and the WHO multinational study of vascular disease in diabetes. BMJ 1998;316:100-5.

12. Dray-Spira R, Gary-Webb TL, Brancati FL. Educational disparities in mortality among adults with diabetes in the U.S. Diabetes Care 2010;33:1200-5.

13. O'Kane MJ, McMenamin M, Bunting BP, et al. The relationship between socioeconomic deprivation and metabolic/cardiovascular risk factors in a cohort of patients with type 2 diabetes mellitus. Prim Care Diabetes 2010;4:241-9.

14. Brown AF, Ettner SL, Piette J, et al. Socioeconomic position and health among persons with diabetes mellitus: a conceptual framework and review of the literature. Epidemiol Rev 2004;26:63-77.

15. Norris SL, Engelgau MM, Venkat Narayan KM. Effectiveness of self-management training in type 2 diabetes: a systematic review of randomized controlled trials. Diabetes Care 2001;24:561-87.

16. Levine DA, Allison JJ, Cherrington A, et al. Disparities in self-monitoring of blood glucose among low-income ethnic minority populations with diabetes, United States. Ethn Dis 2009;19:97-103.

17. Goldman DP, Smith JP. Can patient self-management help explain the SES health gradient? Proc Natl Acad Sci USA 2002;99:10929-34.

18. Walker RJ, Gebregziabher M, Martin-Harris B, et al. Relationship between social determinants of health and processes and outcomes in adults with type 2 diabetes: validation of a conceptual framework. BMC Endoc Dis 2014:14:82.

19. Fisher L, Mullan JT, Skaff MM, et al. Predicting diabetes distress in patients with type 2 diabetes: a longitudinal study. Diabet Med 2009;26:622-7.

20. Kelly SJ, Ismail M. Stress and type 2 diabetes: a review of how stress contributes to the development of type 2 diabetes. Ann Rev Pub Health 2015;36:441-62.

21. Turan B, Osar Z, Molzan Turan J, et al. The role of coping with disease in adherence to treatment regimen and disease control in type 1 and insulin treated type 2 diabetes mellitus. Diabetes Metab 2002;28:186-93.

22. Shayeghian Z, Aguilar-Vafaie ME, Besharat MA, et al. Self-care activities and glycated haemoglobin in Iranian patients with type 2 diabetes: can coping styles and social support have a buffering role? Psychol Health 2015;30:153-64.

23. Tai LA, Tsai LY, Chen SC. Change of glycaemic control and predictors in diabetes patients: longitudinal observational study during one year after hospital discharge. Int J Nurs Prac 2013;19(Suppl 3):28-35.

24. Kapsou M, Panayiotou G, Kokkinos CM, et al. Dimensionality of coping: an empirical contribution to the construct validation of the Brief-COPE with a Greek-speaking sample. J Health Psychol 2010;15:215-29.

25. Tuncay T, Musabak I, Gok DE, et al. The relationship between anxiety, coping strategies and characteristics of patients with diabetes. Health Qual Life Outcomes 2008;6:79.

26. Aung E, Donald M, Williams GM, et al. Joint influence of patient-assessed chronic illness care and patient activation on glycaemic control in type 2 diabetes. Int J Qual Health Care 2015;27:117-24.

27. Worswick J, Wayne SC, Bennett R, et al. Improving quality of care for persons with diabetes: an overview of systematic reviews-what does the evidence tell us? Syst Rev 2013;2:26.
28. Ricci-Cabello I, Ruiz-Perez I, Olry de Labry-Lima A, et al. Do socia inequalities exist in terms of the prevention, diagnosis, treatment, control and monitoring of diabetes? A systematic review. Health Soc Care Community 2010;18:572-87.

29. Cauch-Dudek K, Victor JC, Sigmond M, et al. Disparities in attendance at diabetes self-management education programs after diagnosis in Ontario, Canada: a cohort study. BMC Public Health 2013;13:85.

30. Houle J, Beaulieu MD, Lussier MT, et al. Patient's experience of chronic illness care in a network of teaching settings. Can Fam Physician 2012;58:1366-73.

31. Kogan SM, Brody GH, Chen YF. Depressive symptomatology mediates the effect of socioeconomic disadvantage on $\mathrm{HbA}(1 \mathrm{c})$ among rural African Americans with type 2 diabetes. $J$ Psychosom Res 2009;67:289-96.

32. Cosansu G, Erdogan S. Influence of psychosocial factors on self-care behaviors and glycemic control in Turkish patients with type 2 diabetes mellitus. J Transcult Nurs 2014;25:51-9.

33. Leventhal $\mathrm{H}$, Diefenbach $\mathrm{M}$. The active side of illness cognition. In: Skelton JA, Croyle RT, eds. Mental representation in health and illness. New York: Springer-Verlag, 1991:247-72.

34. Searle A, Norman P, Thompson R, et al. Illness representations among patients with type 2 diabetes and their partners: relationships with self-management behaviors. J Psychosom Res 2007;63:175-84.

35. Moss-Morris R, Weinman J, Petrie KJ. The revised Illness Perception Questionnaire (IPQ-R). Psychol Health 2002;17:1-16.

36. Lange LJ, Piette JD. Personal Models for diabetes in context and patients' health status. J Behav Med 2006;29:239-53.

37. Harvey JN, Lawson VL. The importance of health belief models in determining self-care behavior in diabetes. Diabet Med 2009;26:5-13.

38. Glasgow RE, Hampson SE, Strycker LA, et al. Personal-mode beliefs and social-environmental barriers related to diabetes self-management. Diabetes Care 1997;20:556-61.

39. McSharry J, Moss-Morris R, Kendrick T. Illness perceptions and glycaemic control in diabetes: a systematic review and a meta-analysis. Diabet Med 2011;28:1300-10.

40. Geyer S, Hemström Ö, Peter R, et al. Education, income, and occupational class cannot be used interchangeably in social epidemiology. Empirical evidence against a common practice. $J$ Epidemiol Community Health 2006:60:804-10.

41. Bachman MO, Eachus J, Hopper CD, et al. Socio-economic inequalities in diabetes complications, control, attitudes and health service use: a cross-sectional study. Diabet Med 2003;20: 921-9.

42. Jiang F, Hou X, Lu J, et al. Assessment of the performance of A1CNow+ and development of an error grid analysis graph for comparative hemoglobin A1c measurements. Diabetes Technol Ther 2014:16:363-9.

43. Toobert DJ, Hampson SE, Glasgow RE. The summary of diabetes self-care activities Measure: results from 7 studies and a revised scale. Diabetes Care 2000;23:943-50.

44. Carver CS. You want to measure coping but your protocol's too long: consider the Brief-COPE. Int J Behav Med 1997:4:92-100.

45. Desbiens JF, Fillion L. Coping strategies, emotional outcomes and spiritual quality of life in palliative care nurses. Int $J$ Palliat Nurs 2007:13:291-9.

46. Glasgow RE, Wagner EH, Schaefer J, et al. Development and validation of the Patient Assessment of Chronic Illness Care (PACIC). Med Care 2005:43:436-44.

47. Glasgow RE, Whitesides $\mathrm{H}$, Nelson $\mathrm{CC}$, et al. Use of the Patient Assessment of Chronic Illness Care (PACIC) with patients who have diabetes: relationship to patient characteristics, receipt of care, and self-management. Diabetes Care 2005;28:2655-61.

48. Spitzer RL, Kroenke K, Williams JBW. Validation and utility of a self-report version of PRIME-MD. The PHQ Primary Care Study. JAMA 1999;282:1737-44.

49. Roy T, Lloyd CE, Pouwer F, et al. Screening tools used for measuring depression among people with Type 1 and Type 2 diabetes: a systematic review. Diabet Med 2012;29:164-75.

50. Van der Bijl J, van Poelgeest-Eeltink A, Shortridge-Baggett L. The psychometric properties of the Diabetes Management Self-Efficacy Scale for patients with type 2 diabetes mellitus. J Adv Nurs 1999;30:352-9.

51. McDowell J, Courtney M, Edwards H. Validation of the Australian/ English version of the diabetes management self-efficacy scale. Int $J$ Nurs Pract 2005;11:177-84.

52. Preacher KJ, Hayes AF. SPSS and SAS procedures for estimating indirect effects in simple mediation models. Behav Res Meth Inst Comp 2004;36:717-31. 
53. Preacher KJ, Hayes AF. Asymptotic and resampling strategies for assessing and comparing indirect effects in multiple mediator models. Behav Res Meth 2008;40:879-91.

54. MacKinnon DP, Lockwood CM, Hoffman JM, et al. A comparison of methods to test mediation and other intervening variable effects. Psychol Meth 2002;7:83-104.

55. Frazier PA, Tix AP, Barron KE. Testing moderator and mediator effects in counseling psychology research. $J$ Couns Psychol 2004;51:115-34.

56. Luyckx K, Vanhalst J, Seiffge-Krenke I, et al. A typology of coping with type 1 diabetes in emerging adulthood: associations with demographic, psychological, and clinical parameters. J Behav Med 2010;33:228-38

57. Luyckx K, Seiffge-Krenke I, Hampson SE. Glycemic control, coping, and internalizing and externalizing symptoms in adolescents with type 1 diabetes. A cross-lagged longitudinal approach. Diabetes Care 2010;33:1424-9.

58. Fleurbaey M, Schokkaert E. Unfair inequalities in health and health care. J Health Econ 2009;28:73-90.

59. Adler NE, Rehkopf DH. U.S. disparities in health: descriptions, causes, and mechanisms. Ann Rev Public Health 2008;29: 235-52.

60. De Ridder D, Schreurs K. Developing interventions for chronically ill patients: is coping a helpful concept? Clin Psychol Rev $2001 ; 21: 205-40$.

61. Wang JL, Schmitz N, Dewa CS. Socioeconomic status and the risk of major depression: the Canadian National Population Health Survey. J Epidemiol Community Health 2010;64:447-52.

62. Pouwer F, Nefs G, Nouwen A. Adverse effects of depression on glycemic control and health outcomes in people with diabetes: a review. Endocrinol Metab Clin North Am 2013;42:529-44.

63. Baumeister $\mathrm{H}$, Hutter N, Bengel J. Psychological and pharmacological interventions for depression in patients with diabetes mellitus: an abridged Cochrane review. Diabet Med 2014;31:773-86.

64. Houle J, Beaulieu MD, Lespérance F, et al. Inequities in medical follow-up for depression: a population-based study in Montreal. Psychiatr Serv 2010;61:258-63.

65. Huot KL, Luftiyya MN, Akers MF, et al. A population-based cross-sectional study of health service deficits among U.S. adults with depressive symptoms. BMC Health Serv Res 2013;13:160.

66. Lin EHB, Katon W, Von Korff M, et al. Relationship of depression and diabetes self-care, medication adherence, and preventive care. Diabetes Care 2004;27:2154-60.

67. Nicolau J, Rivera R, Francés C, et al. Treatment of depression in type 2 patients who have diabetes: effects on depressive symptoms, quality of life and metabolic control. Diabetes Res Clin Pract 2013:101:148-52.

68. Schillinger D, Barton LR, Karter AJ, et al. Does literacy mediate the relationship between education and health outcomes? A study of a low-income population with diabetes. Public Health Rep 2006;121:245-54.

69. Berkowitz SA, Karter AJ, Lyles CR, et al. Low socioeconomic status is associated with increased risk for hypoglycemia in diabetes patients: the Diabetes Study of Northern California (DISTANCE). $J$ Health Care Poor Underserved 2014:25:478-90.

70. Keogh KM, Smith SM, White P, et al. Psychological family interventions for poorly controlled type 2 diabetes. Am J Managed Care 2011;17:105-13.
71. Tucker CM, Lopez MT, Campbell K, et al. The effects of a culturally sensitive, empowerment-focused, community-based health promotion program on health outcomes of adults with type 2 diabetes. J Health Care Poor Underserved 2014:25:292-307.

72. Henderson J, Wilson C, Roberts L, et al. Social barriers to type 2 diabetes self-management: the role of capital. Nurs Inquiry 2014:21:336-45.

73. Weaver RR, Lemonde M, Payman N, et al. Health capabilities and diabetes self-management: the impact of economic, social and cultural resources. Soc Sci Med 2014;102:58-68.

74. Drouin S, Hamelin AM, Ouellet D. Economic access to fruits and vegetables in the greater Quebec City: do disparities exist? Can J Public Health 2009;100:361-4.

75. Booth GL, Creatore MI, Moineddin R, et al. Unwalkable neighborhoods, poverty, and the risk of diabetes among recent immigrants to Canada compared with long term residents. Diabetes Care 2013;36:302-8.

76. Sudore RL, Mehta KM, Simonsick EM, et al. Limited literacy in older people and disparities in health and healthcare access. J Am Geriatr Soc 2006;54:770-6.

77. Reyna VF, Nelson WL, Han PK, et al. How numeracy influences risk comprehension and medical decision making. Psychol Bull 2009;135:943-73

78. White RO, Eden S, Wallston KA, et al. Health communication, self-care, and treatment satisfaction among low-income diabetes patients in a public health setting. Patient Educ Couns 2015;98:144-9.

79. Chaufan $\mathrm{C}$, Weitz $\mathrm{R}$. The elephant in the room: the invisibility of poverty in research on type 2 diabetes. Hum Soc 2009;33:74-98.

80. Raphael D, Anstice S, Raine K, et al. The social determinants of the incidence and management of type 2 diabetes mellitus: are we prepared to rethink our questions and redirect our research activities? Leadership Health Serv 2003;16:10-20.

81. Yu VL, Raphael D. Identifying and addressing the social determinants of the incidence and successful management of type 2 diabetes mellitus in Canada. Can J Public Health 2004;95:366-8.

82. Christie A. Are there intervention-generated inequalities in type 2 diabetes care? A systematic review and analysis of routine data [Doctoral dissertation]. Durham University, 2014.

83. Bebb C, Kendrick D, Stewart J, et al. Inequalities in glycaemic control in patients with Type 2 diabetes in primary care. Diabet Med 2005;22:1364-71.

84. Carey ME, Mandalia PK, Daly H, et al. Increasing capacity to deliver diabetes self-management education: results of the DESMOND lay educator non-randomized controlled equivalence trial. Diabet Med 2014;31:1431-8.

85. APA Task Force on Socioeconomic Status. Report of the APA task force on socioeconomic status. Washington: American Psychological Association, 2007

86. Rizza RA, Mandarino J, Gerich JE. Cortisol-induced insulin resistance in man: impaired suppression of glucose production and stimulation of glucose utilization due to a postreceptor defect of insulin action. J Clin Endocrinol Metab 1982;54:131-8.

87. Bode BW, Irvin BR, Pierce JA, et al. Advances in hemoglobin A1c point of care technology. J Diabetes Sci Technol 2007;1:405-11.

88. Alleyn CR, Laffel LMB, Volkening LK, et al. Comparison of longitudinal point-of-care and high-performance liquid chromatography $\mathrm{HbA} 1 \mathrm{c}$ measurements in a multi-centre trial. Diabet Med 2011;28:1525-9. 